\title{
Acceleration Characteristics of a Rock Slide Using the Particle Image Velocimetry Technique
}

\author{
Guoqing Chen, Le Li, Cong Zhao, Runqiu Huang, and Fan Guo \\ State Key Laboratory of Geohazard Prevention and Geoenvironment Protection, Chengdu University of Technology, \\ Chengdu, Sichuan 610059, China \\ Correspondence should be addressed to Guoqing Chen; chgq1982@126.com
}

Received 26 December 2015; Revised 28 February 2016; Accepted 29 February 2016

Academic Editor: Fei Dai

Copyright (C) 2016 Guoqing Chen et al. This is an open access article distributed under the Creative Commons Attribution License, which permits unrestricted use, distribution, and reproduction in any medium, provided the original work is properly cited.

The Particle Image Velocimetry (PIV) technique with high precision and spatial resolution is a suitable sensor for flow field experiments. In this paper, the PIV technology was used to monitor the development of a displacement field, velocity field and acceleration field of a rock slide. It was found that the peak acceleration of the sliding surface appeared earlier than the peak acceleration of the sliding body. The characteristics of the rock slide including the short failure time, high velocities, and large accelerations indicate that the sliding forces and energy release rate of the slope are high. The deformation field showed that the sliding body was sliding outwards along the sliding surface while the sliding bed moved in an opposite direction. Moving upwards at the top of the sliding bed can be one of the warning signs for rock slide failure.

\section{Introduction}

With an increasing number of large engineering projects such as hydropower engineering, national defense project construction and road construction are implemented in mountain areas; the change of climate and the environment pollutions cause the rock slide hazard to frequently happen. The sliding body rotating along the sliding surface with high speed and high energy [1] has been released. So the failure mechanisms of large-scale rock slides need more attention since the brittle failure time is short.

The stability of rock slides was investigated through surface displacement measurements [2]. During the process of progressive failure, the cracks developing at the sliding surface can be used to reflect the stability of the slope [3-5]. Microseism [6-8] and acoustic emission techniques [9, 10] can reflect the process of rock failure and be applied for early warning techniques. Comprehensive measures such as the finite-element analysis [11, 12], reinforcement techniques [13], multivariate information $[14,15]$ and dynamic design methodology [16] were commonly used to deal with these slope stability problems.

Laboratory tests such as shaking table tests [17], ring shear tests [18], 3D resistivity tomography [19], ground-based radar interferometry [20], fiber monitoring network [21-23], Fiber Bragg Gratings sensing bars (FBG) [24], and Particle Image Velocimetry (PIV) [25-30] were used to study the mechanism of slope instability. However, the failure form of the rock slide is brittle failure, and the failure time is short. The whole failure situation of the rock slide cannot be obtained by using the above methods, and the specific temporal deformation trend of rock slide cannot be obtained.

The PIV technique was commonly applied to monitor displacement fields [17, 28-30] and strain fields [27] for the rock slope failure. However, the velocity and acceleration field of the slope body were seldom analyzed. In this paper, the PIV technique was used to study the velocity field and the acceleration field during the slope failure process. The failure pictures of rock slope were collected by using high-speed camera, and the velocity vectors were obtained by using this sensor technology. The instantaneous forces about the failure mechanism of rock slide were analyzed.

\section{PIV Sensor and Experiment Preparations}

2.1. The Principle of the PIV System. By using the efficient image processing technology, PIV have achieved good sensor 
TABLE 1: Material mix ratio of each part of the slope (g).

\begin{tabular}{lcccccrr}
\hline Zone & Cement & Gypsum powder & Quartz sand & Water & Mixture ratio & $C(\mathrm{MPa})$ & $\Phi\left(^{\circ}\right)$ \\
\hline I & 38 & 95 & 285 & 66.5 & $0.4: 1.3: 0.7$ & 2.3 & 30.4 \\
III & 21 & 47 & 146 & 35 & $0.7: 1.3: 0.7$ & 4.0 & 38.9 \\
\hline II & 1955 & 1955 & 5865 & 1368 & $1: 1.3: 0.7$ & 4.5 & 48.2 \\
\hline IV & & & & & & \\
\hline
\end{tabular}

results in fluid mechanics. Combining the advantages of both single-point and display measurements, the PIV system not only contains the precision and resolution of single-point measurements but also obtains the overall flow field and transient images.

The PIV system automatically distributes the tracer particle in the whole sliding slope through a two-dimensional plane. The particles move with slope collapsing, so the displacement and velocity are easily obtained by locating the trajectories of all particles between two pictures. Given the particle trajectory between two pictures, the velocities along the $X$ direction and the $Y$ direction are determined according to

$$
\begin{aligned}
& v_{x}=\frac{d x(t)}{d t}=\frac{x(t+\Delta t)-x(t)}{\Delta t}=\overline{v_{x}}, \\
& v_{y}=\frac{d y(t)}{d t}=\frac{y(t+\Delta t)-y(t)}{\Delta t}=\overline{v_{y}},
\end{aligned}
$$

where the displacements $x$ and $y$ are a function of time $t$ which can be expressed by the functions $x(t)$ and $y(t)$; $t$ is the current time; $\Delta t$ is the time interval, which is $0.02 \mathrm{~s}$ in this paper; $\overline{v_{x}}$ and $\overline{v_{y}}$ are the instantaneous average velocities in the $x$ and $y$ directions over $\Delta t$.

2.2. Experimental Materials and Test Principle. The test model is processed into $300 * 300 * 50 \mathrm{~mm}^{3}$. The model imitates a three-step failure of sliding slope (Figure 1). Step one is creep along the horizontal soft stratum in the lower part of slope (see III in Figure 1), step two is tension at the back edge (see I in Figure 1), and step three is shearing of the locking section in the middle of the sliding surface (see II in Figure 1). Eight monitoring points were selected in the rock slide (see Figure 1). Point (1) is at the top of the sliding slope, Points (2), (3), and (4) are at the potential sliding surface, Point (5) and Point (6) are at the potential sliding body, Point (7) is at the bottom of sliding bed, and Point (8) is at the middle part of sliding bed. The specifications of the sliding slope, position of the monitoring points, mechanical parameters, and material characteristics are shown in Figure 1 and Table 1. $c$ and $\varphi$ are determined from the direct shear test.

2.3. PIV Monitoring Solutions and Experiment Scheme. The acquisition frequency of the PIV system is $50 \mathrm{~Hz}$ and the pixel resolution of the camera is $2048 * 2048$. The slope model was fixed in a test frame and the camera was placed in front of the model (Figure 2). The jack pressure was prepared to be added after the installation of the equipment. The pressure jack was set on the preset load part of the model; then the pressure was added step by step with a constant velocity.

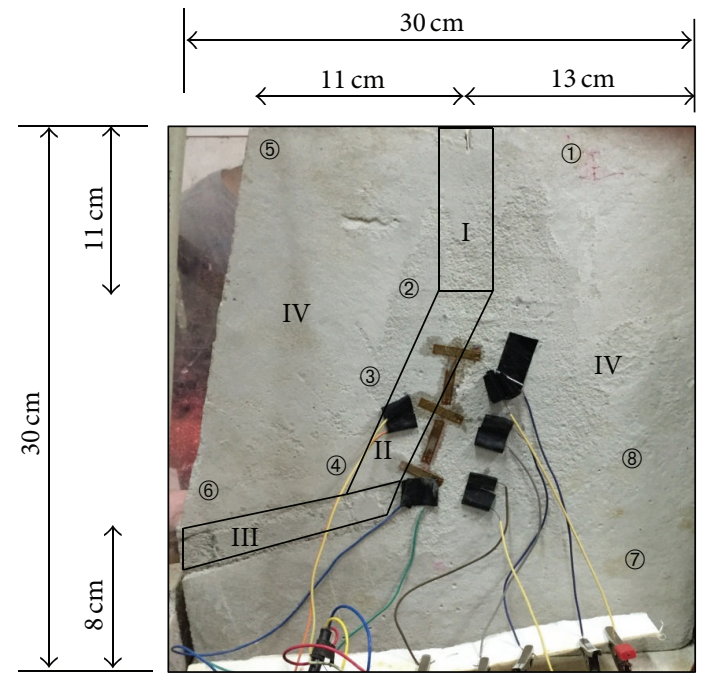

FIGURE 1: Rock slide with monitoring points and different materials $(300 \mathrm{~mm} * 300 \mathrm{~mm})$.

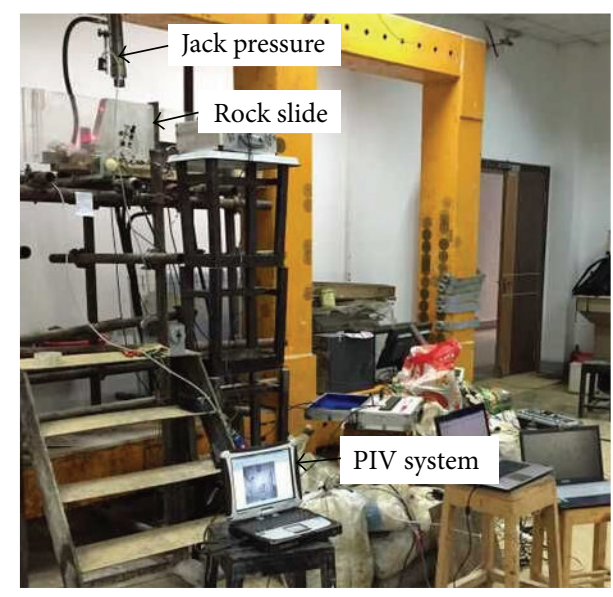

FIGURE 2: PIV rock slide experiment field.

Velocity field and displacement field were collected since the experiment started and transformed by using PIV sensor. The velocity of the sliding slope was calculated by the displacement field; then the acceleration field was obtained according to the velocity field in the process of failure.

\section{Experimental Results and Analysis}

3.1. Extension of Cracks and Sliding Surface. The test model simulated the failure of the three-step sliding slope, the rock 


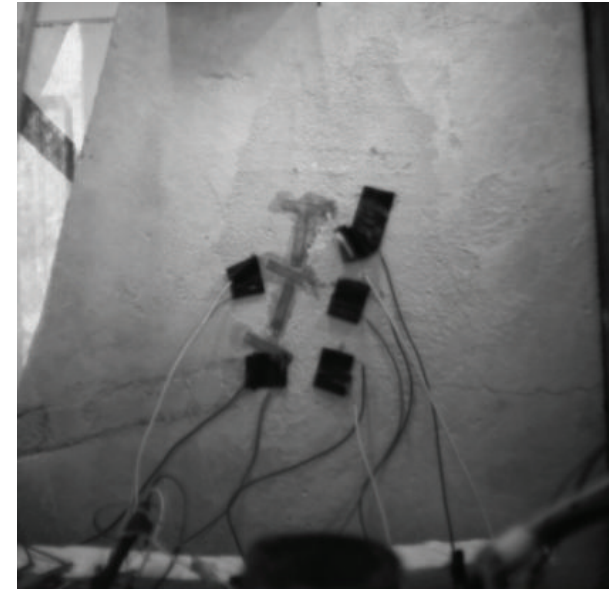

(a) $0 \mathrm{~s}$ before failure

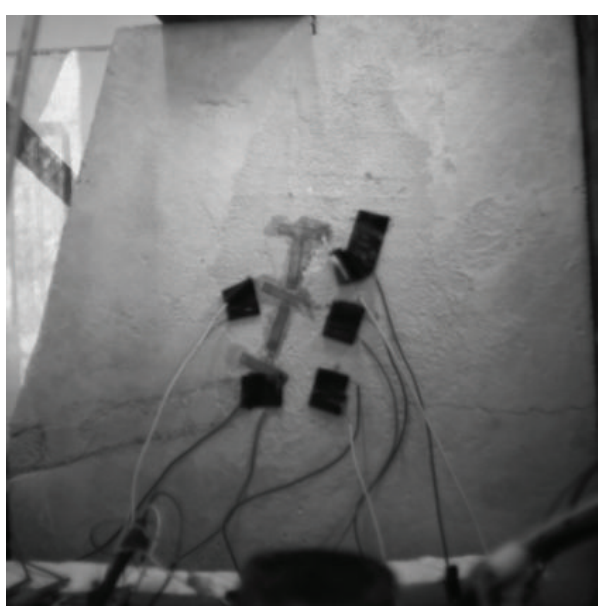

(c) $0.04 \mathrm{~s}$ crack at the top

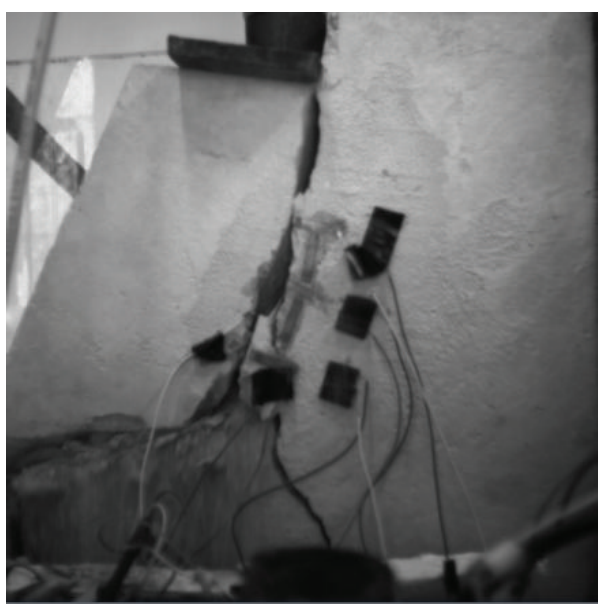

(e) $0.08 \mathrm{~s}$ crack coalescence

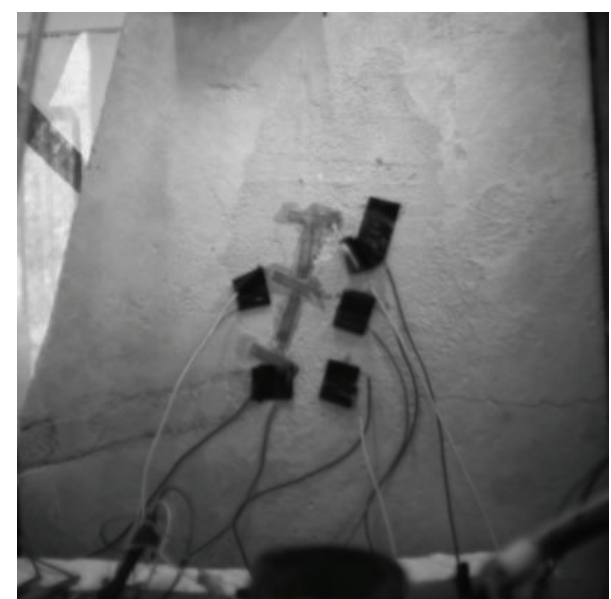

(b) $0.02 \mathrm{~s}$ crack initiation

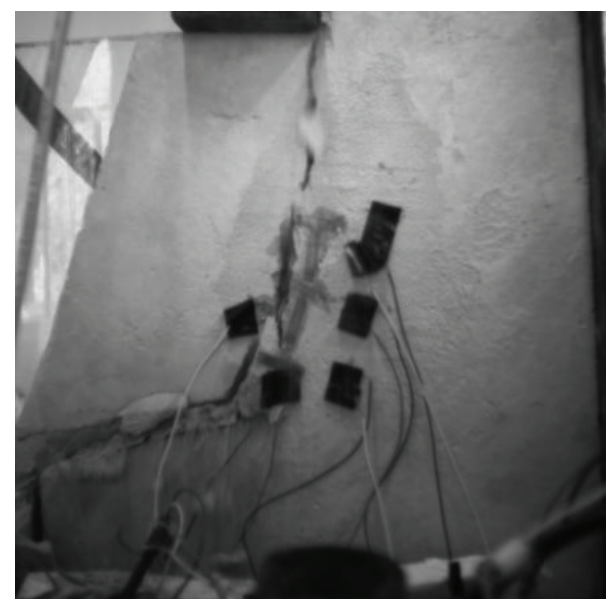

(d) $0.06 \mathrm{~s}$ crack propagation

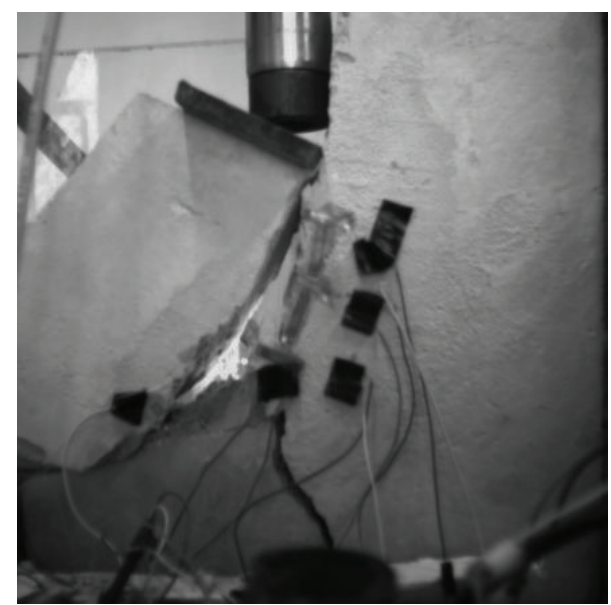

(f) $0.1 \mathrm{~s}$ sliding body dumped

FIGURE 3: Extension of cracks during the failure process of the rock slide.

slope had failed in the experiment when the jack pressure reached $7 \mathrm{MPa}$. The temporal and spatial evolution process of failure cracks was obtained by the high-speed camera of the PIV system (Figure 3).
Figure 3 shows that the failure of the rock slope was characterized as instantaneous rotating of the sliding body. It can be seen from Figure 3 that the tension crack appeared at the top of the slope at $0.04 \mathrm{~s}$; then, the crack developed at 


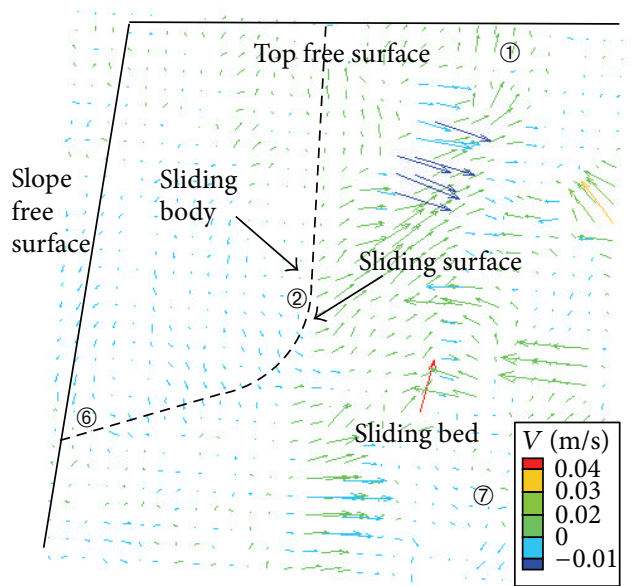

(a) $0.02 \mathrm{~s}$

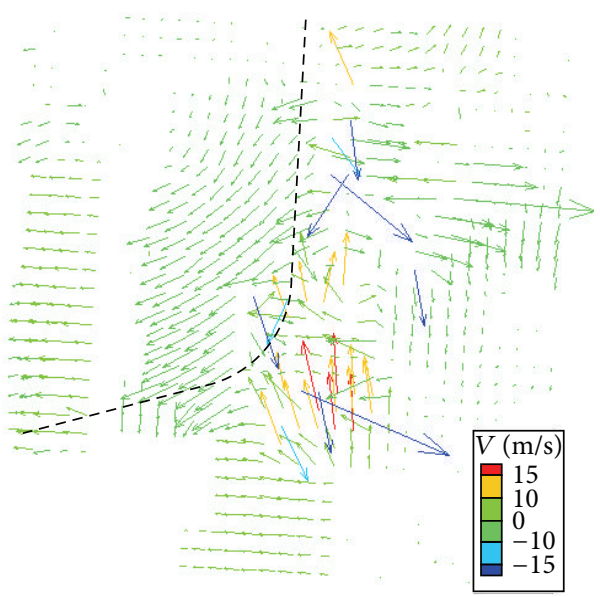

(c) $0.06 \mathrm{~s}$

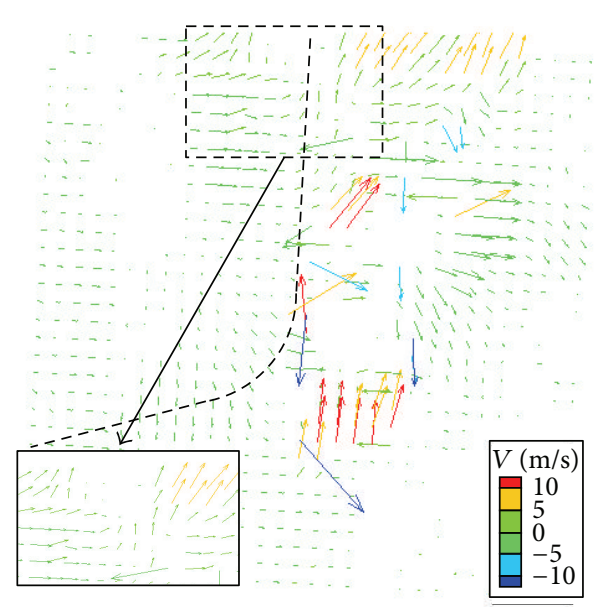

(b) $0.04 \mathrm{~s}$

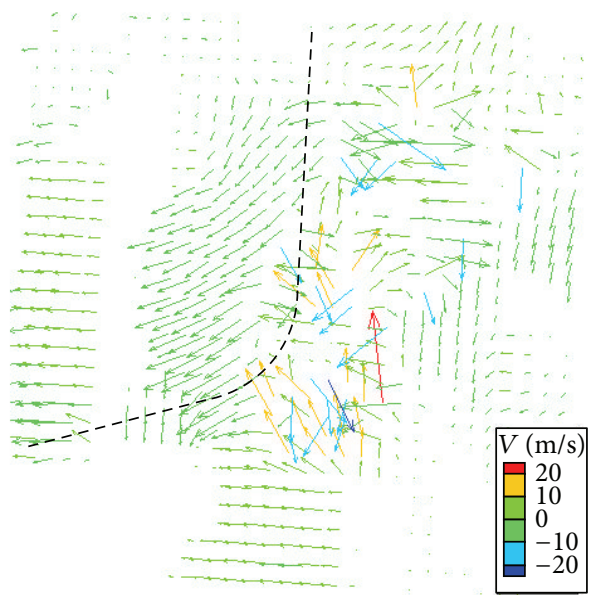

(d) $0.08 \mathrm{~s}$

FIGURE 4: Changes of the velocity field during rock slide failure $(300 \mathrm{~mm} * 300 \mathrm{~mm})$.

$0.06 \mathrm{~s}$ and the crack coalescence with the sliding body failure occurred at $0.08 \mathrm{~s}$. Thereafter, the sliding body rotated along the direction of sliding bed. The rock slide was completely destroyed at $0.1 \mathrm{~s}$ and the whole sliding surface presented a trend of circular shape movement.

3.2. Velocity Field and Displacement Field. With the highspeed camera and sensor technology in the PIV, the velocity field (Figure 4) and displacement field are obtained (Figure 4) (the positive values correspond to the left direction of the vectors and the negative value corresponds to the right direction in Figures 4 and 5).

Figure 4(a) shows that the moving direction and velocity differ in various parts of the slope. Point (6) in the sliding body moved towards the sliding bed with a velocity of $-0.05 \mathrm{~m} / \mathrm{s}$ at $0.02 \mathrm{~s}$; then, it moved towards the slope free surface with a velocity of $0.05 \mathrm{~m} / \mathrm{s}$ at $0.04 \mathrm{~s}$ and continued moving towards the slope free surface with the velocity of $0.71 \mathrm{~m} / \mathrm{s}$ at $0.06 \mathrm{~s}$. The other vectors of the sliding body show the circular trajectory.
The velocity field around Point (1) (Figure 4(a)) which is at the top of the slope is orientated in an upper right direction. The velocity of Point (1) was almost zero at $0.04 \mathrm{~s}$, but then it reached a velocity of $-5.73 \mathrm{~m} / \mathrm{s}$ at $0.06 \mathrm{~s}$. The tension crack appeared on the top of the slope at this moment (Figure 3(c)); then, the coalescence of the failure surfaces generated the instability (Figure 3(d)). Therefore, the upward moving phenomenon at the top of the slope can be used as a warning sign for rock slide failure. Point (2) moved along the sliding surface with a relatively high velocity. Point (7) and Point (8) in the sliding bed both moved in an opposite direction of the movement along the sliding surface with a relatively low velocity but Point 8 moved quicker than Point (7). Since Point (8) is in the middle of the sliding bed while Point (7) is in the bottom of the sliding bed, this phenomenon shows that different part of the sliding bed can have different failure and the deep region of the rock slope does not have a large amount of deformation.

The changes of displacement field showed the deformation of the rock slide during the failure. Points (1), (2), (6), 


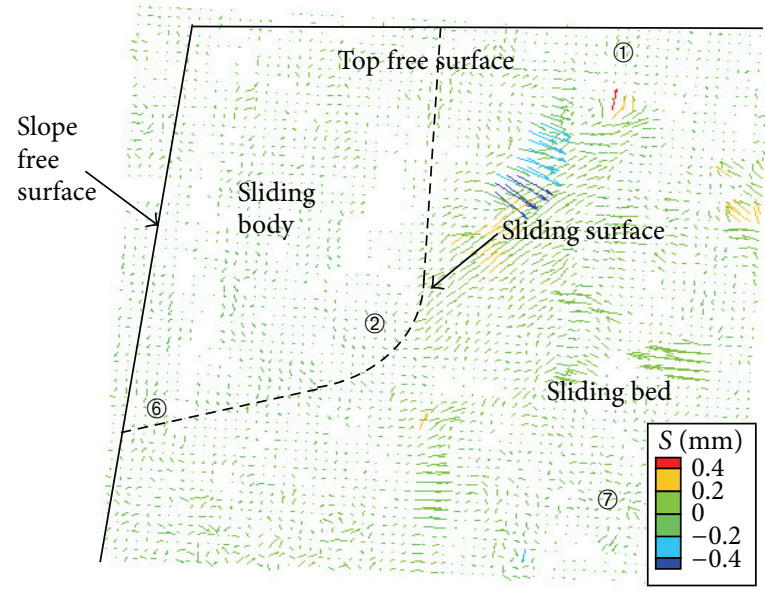

(a) $0 \sim 0.02 \mathrm{~s}$

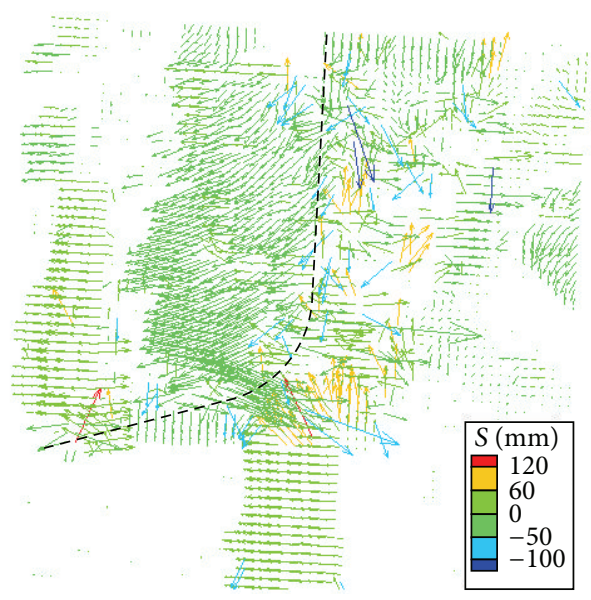

(c) $0.04 \sim 0.06 \mathrm{~s}$

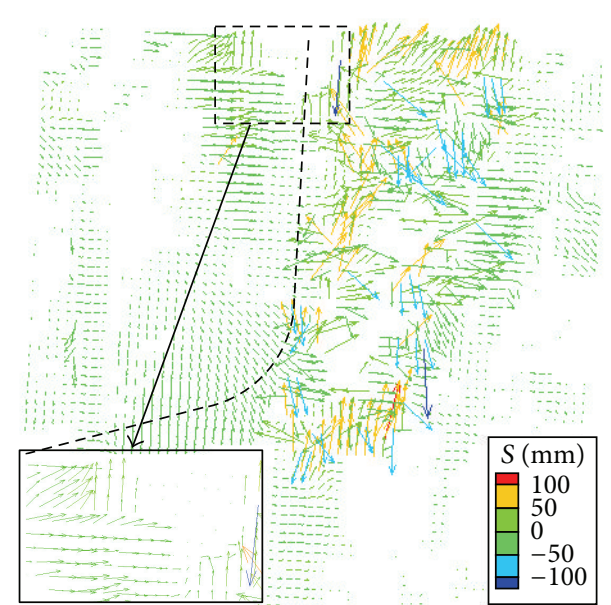

(b) $0.02 \sim 0.04 \mathrm{~s}$

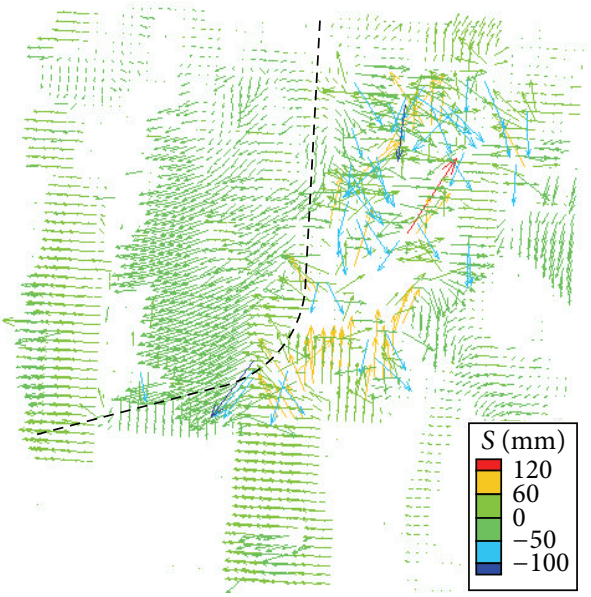

(d) $0.06 \sim 0.08 \mathrm{~s}$

FIGURE 5: Changes of the displacement field during rock slide failure $(300 \mathrm{~mm} * 300 \mathrm{~mm})$.

and (7) were selected for analyzing the displacement field. The displacement of Point (2) was $0.5 \mathrm{~mm}$ at $0.02 \mathrm{~s}, 7.5 \mathrm{~mm}$ at $0.04 \mathrm{~s}$, and $75 \mathrm{~mm}$ at $0.06 \mathrm{~s}$, respectively. This shows that the tension crack started to appear at the top of the slope at $0.02 \mathrm{~s}$ and increases with time quickly. The displacement of the various parts gradually increased with the coalescence of the sliding surface. Figure 5 showed that the displacement field of Point (6) in the sliding body also follows the circular trajectory: the point in the sliding body first moves towards the sliding bed (Figure 5(b)), then towards the slope free surface, and finally dumps along the sliding surface.

It can be seen from Figures 4 and 5 that the deformations at the bottom of the rock slope such as Point (7) are almost zero, which means the failure has little influence at the deep region of the rock slope. It can be concluded that each part of the rock slope has different law of motion and the displacement of each part in the rock slope is discontinuous.

In addition to the velocity and displacement, the variation of the velocity and displacement versus time of the 8 monitoring points at the slope is summarized in Figures 6-9. The mean value of displacement and velocity (Tables 2 and 3) is observed for the temporal and spatial evolution regularity of the sliding slope (the positive values correspond to the downside of the vectors and the negative value corresponds to the upper side in Figures 6-9).

Table 2 showed that the velocity along the sliding surface is the highest $(20 \mathrm{~m} / \mathrm{s})$, and the velocity of the sliding bed is relatively small. Figure 6 shows that the velocity of Point (1) was $-5.71 \mathrm{~m} / \mathrm{s}$ at $0.06 \mathrm{~s}$ while the other point in the sliding surface was almost zero at that time; this was the beginning moment of rock slope failure. It can be seen from Figure 6 that the velocities of Point (5) and Point (6) are different, and the sliding bed and the sliding surface have the same phenomenon.

It can be seen from Figures 8 and 9 that the displacement increases with failure time. The failure happened in the sliding body first, then the sliding body start to collapsed at a uniform velocity, and finally the deformation comes into a accelerative stage until the complete failure of the slope. It can be seen from Table 3 that the average deformation on the sliding surface is the largest $(0.29 \mathrm{~m})$ and the average deformation on the sliding bed is relatively small $(0.1 \mathrm{~m})$. 
TABLE 2: Velocity evolution versus time $(\mathrm{m} / \mathrm{s})$.

\begin{tabular}{lcccc}
\hline & The top of rock slide & Sliding surface & Sliding body & Sliding bed \\
\hline \multirow{2}{*}{ Initial stage $(0 \sim 0.04 \mathrm{~s})$} & -0.03 & 0.05 & -0.02 & 0 \\
& 0 & 0.01 & -0.02 & -0.01 \\
\hline \multirow{2}{*}{ The coalescence stage $(0.04 \sim 0.08 \mathrm{~s})$} & -5.73 & 0.41 & 0.35 & -0.41 \\
& -2.91 & 8.20 & 2.48 & 4.36 \\
The postcoalescence stage $(0.08 \sim 0.12 \mathrm{~s})$ & -6.00 & 10.68 & 4.71 & -1.98 \\
\end{tabular}

TABLE 3: Displacement evolution versus time (m).

\begin{tabular}{|c|c|c|c|c|}
\hline & The top of rock slide & Sliding surface & Sliding body & Sliding bed \\
\hline \multirow{2}{*}{ Initial stage $(0 \sim 0.04 \mathrm{~s})$} & 0 & 0 & 0 & 0 \\
\hline & -0.05 & 0.02 & -0.01 & -0.01 \\
\hline \multirow{2}{*}{ The coalescence stage $(0.04 \sim 0.08 \mathrm{~s})$} & -0.14 & 0.11 & 0.01 & -0.01 \\
\hline & -0.23 & 0.29 & 0.10 & -0.04 \\
\hline The postcoalescence stage $(0.08 \sim 0.12 \mathrm{~s})$ & -0.36 & 0.53 & 0.19 & -0.08 \\
\hline
\end{tabular}

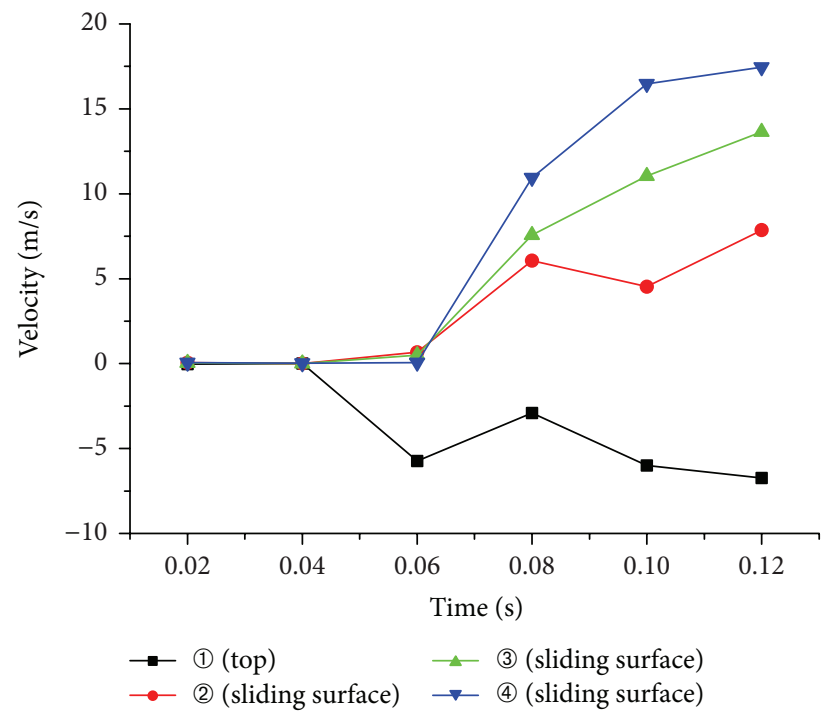

Figure 6: Change of the velocity with time of Points (1) (4).

3.3. Acceleration Characteristic. Acceleration and the internal instantaneous force can be obtained by (2) with a change in the velocity field over $t$ :

$$
\begin{aligned}
& a=\frac{v_{t+\Delta t}-v_{t}}{\Delta t}, \\
& F=m \times a,
\end{aligned}
$$

where $\Delta t$ is the time interval $(0.02 \mathrm{~s}) ; v_{t}$ is velocity of the previous time; $v_{t+\Delta t}$ is velocity of next time; $m$ is the particle mass. The mass of a unit volume of $1 \mathrm{~cm}^{3}$ of a particle is taken as a unit mass in this experiment. $a$ is acceleration, $F$ is instantaneous force at that point.

The variation of the acceleration versus time is shown in Figures 10 and 11. The sequences of the mean variation in acceleration which is taken as the mean value are shown in Table 4 . It can be seen from Figure 10 that the maximum

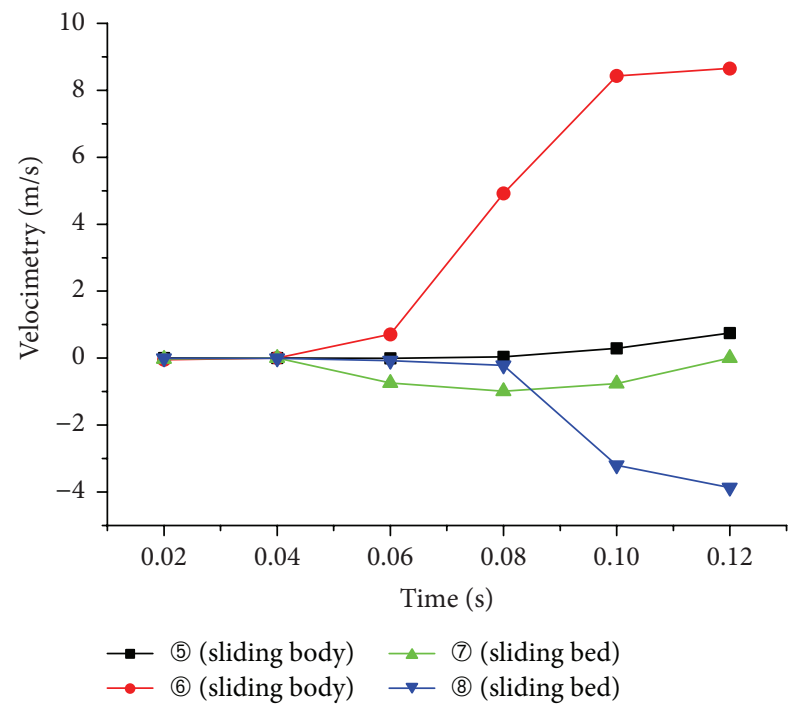

FIGURE 7: Change of the velocity with time of Points (5) (8).

acceleration can reach a value of $500 \mathrm{~m} / \mathrm{s}^{2}$ that indicates strong instantaneous forces and high energy release during rock slope failure. Figures 10 and 11 show that the acceleration of the sliding surface and the sliding body reached maximum at $0.06 \mathrm{~s}$. This indicates that the sliding surface and the sliding body fail at the same time. The instantaneous force at this moment is high. In addition, the acceleration at the top of the sliding body reached peak at $0.04 \mathrm{~s}$ while the sliding surface reached peak at $0.06 \mathrm{~s}$, which means the instantaneous force is relatively high and the sliding surface is not completely coalescing at this moment.

Acceleration indirectly reflects the magnitude of the force. The acceleration of the top of sliding bed increases significantly at $0.04 \mathrm{~s}$ (Figure 10), and the acceleration of sliding surface and sliding body, respectively, increases rapidly at $0.06 \mathrm{~s}$ (Figures 10 and 11). Table 4 indicates that the 
TABLE 4: Acceleration evolution versus time $\left(\mathrm{m} / \mathrm{s}^{2}\right)$.

\begin{tabular}{lcccc}
\hline & The top of rock slide & Sliding surface & Sliding body & Sliding bed \\
\hline \multirow{2}{*}{ Initial stage $(0 \sim 0.04 \mathrm{~s})$} & -1.50 & -2.17 & 1.25 & -0.50 \\
& -286.50 & 20.00 & -20.25 \\
\hline \multirow{2}{*}{ The coalescence stage $(0.04 \sim 0.08 \mathrm{~s})$} & 14.10 & 386.33 & 17.5 & -9.75 \\
& -154.50 & 124.00 & 94.5 & -68.75 \\
\hline The postcoalescence stage $(0.08 \sim 0.12 \mathrm{~s})$ & 36.50 & 115.00 & 17.25 \\
\hline
\end{tabular}

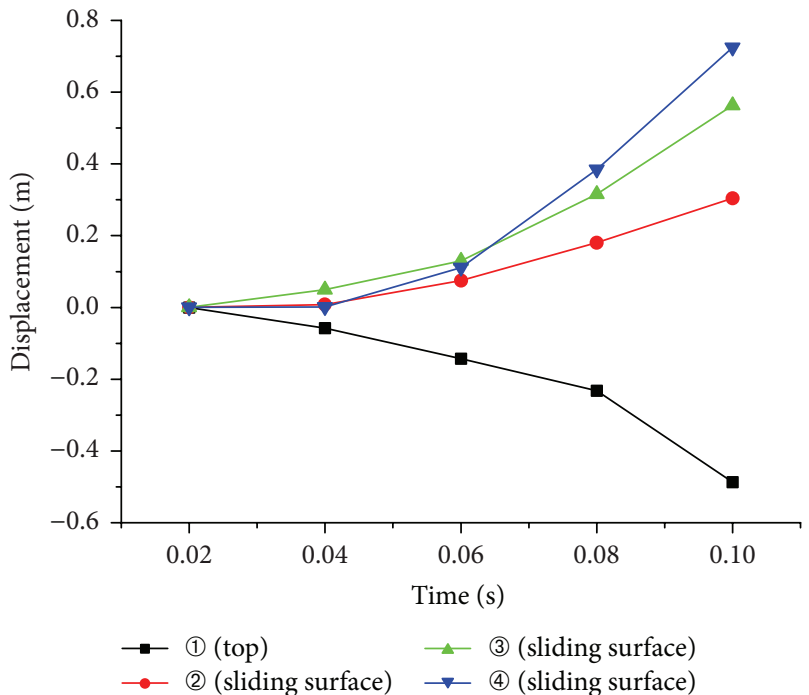

FIgUre 8: Change of the displacement with time of Points (1) (4).

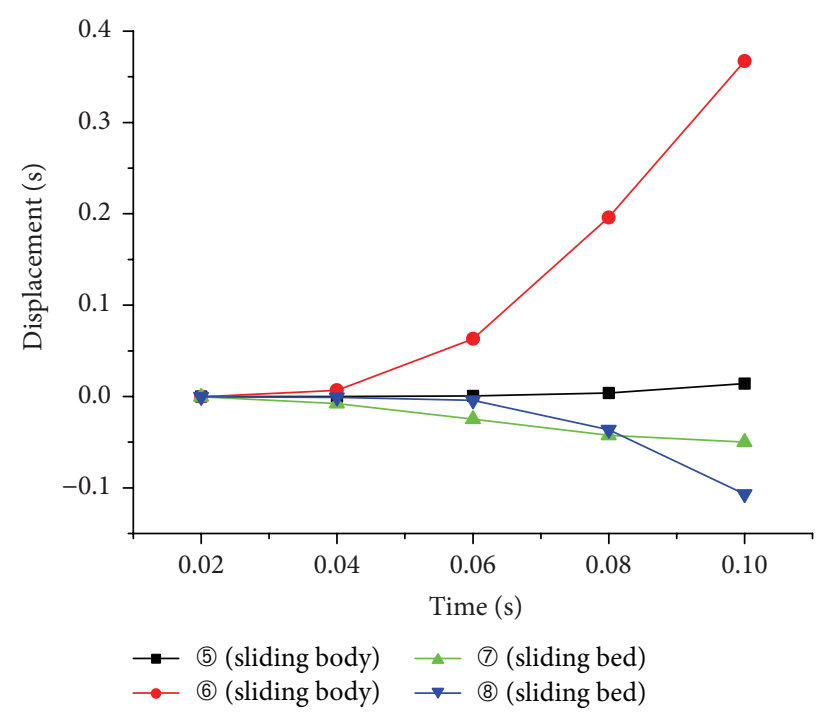

FIgure 9: Change of the displacement with time of Points (5) (8).

acceleration of each particle suddenly increased when the sliding surface coalesced, and the force reached a peak at this moment. Therefore, a trend of displacement at the top of the sliding slope can be considered as the beginning of the failure for the rock slide.

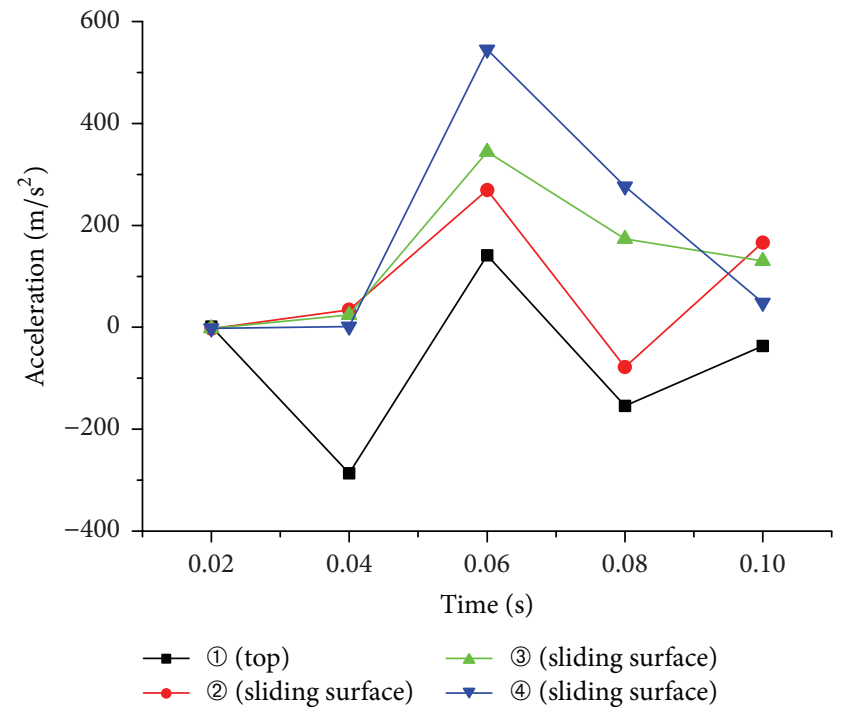

Figure 10: Points (1) (4) acceleration versus time.

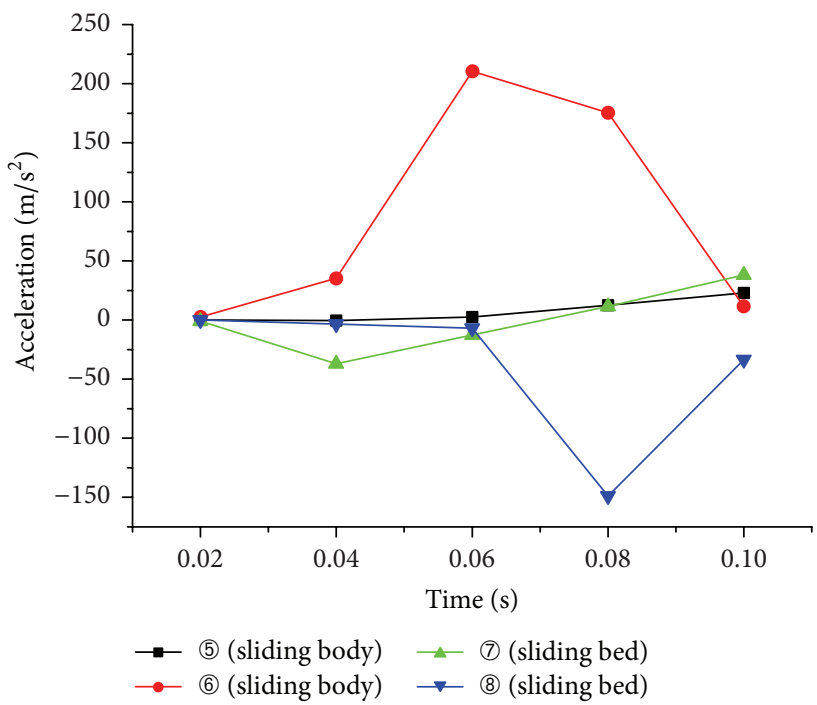

FIgURE 11: Points (5) (8) acceleration versus time.

\section{Discussion and Conclusion}

A rock slide failure experiment was carried out and the slope failure trajectory had been analyzed based on the PIV technology. Many deficiencies were also found in this experiment: (1) only the deformation on the exterior of the 
model in a two-dimensional plane can be monitored with the PIV equipment. The development of the internal crack needs to be monitored with other techniques, such as acoustic emission. (2) The PIV camera was placed at a long distance in order to avoid brittle failure. Additionally, other devices placed on the rock surface (like strain gauges) will disrupt the vector lines of the moving mass when the rock failure is completely destroyed. This leads to some disruption of the vector lines, which will have a certain impact on the accuracy of the final data (Figures 4 and 5). (3) In this experiment, the influence of model dimension was not considered; the position of jack pressure can also make an influence on model test. During the rock slope failure, the internal friction may become a factor for the upward moving phenomenon at the top of the sliding bed, which needs further discussion and exploration.

The conclusion can be summarized as follows:

(1) PIV observes the temporal and spatial evolution regularity of the motion parameters for the whole rock slide. By using high-speed camera and the sensor technology, the failure pictures for rock slide are transformed into velocity and displacement vectors. Trials found that the crack first appeared on the top of the slope, then the sliding surface collapsed, and the sliding body failed with a circular shape. Finally the sliding body completely dumped, and the rock slide failure was finished.

(2) It can be concluded that the direction of the displacement of the sliding body is first towards the slope bed side, and then it turns to the slope free surface and finally continues moving towards the slope free surface; the velocity is relatively high. The sliding bed moves to the opposite direction and the velocity is relatively small. It can also be found that the points in the same part of the rock slope can also have different law of motion and the deep region of the rock slope does not have a large amount of deformation.

(3) The acceleration of the different parts of the rock slide reaches maximum at different moments: the top of the sliding bed reaches the peak first, followed by the sliding surface and the sliding body. The maximum acceleration appears in the sliding surface, which means a high energy release for the rock slide. The upward movement of the top of the sliding bed can be a warning sign for rock slide failure.

\section{Competing Interests}

The authors declare that they have no competing interests.

\section{Acknowledgments}

This work is supported by the National Basic Research Program of China (973 Program, no. 2013CB733202) and the National Natural Science Foundation of China (Grant nos. 41130745, 41572283, and 41272330). This work is also supported by the funding of Science and Technology Office of Sichuan Province (Grant no. 2015JQ0020). This work is supported by the Research Fund of the State Key Laboratory of Geohazard Prevention and Geoenvironment Protection (Chengdu University of Technology) under Grant nos. SKLGP2012Z003 and SKLGP2009Z015.

\section{References}

[1] R. Q. Huang, G. Q. Chen, F. Guo, G. F. Zhang, and Y. Zhang, "Experimental study on the brittle failure of the locking section in a large-scale rock slide," Landslides, 2016.

[2] G. Q. Chen, R. Q. Huang, Q. Xu, and T. B. Li, "Prevention of the natural landslide disaster based on the deformation management level," Disaster Advances, vol. 5, no. 4, pp. 13071312, 2012.

[3] X.-T. Feng and M. Seto, "Fractal structure of the time distribution of microfracturing in rocks," Geophysical Journal International, vol. 136, no. 1, pp. 275-285, 1999.

[4] C.-S. Tang, B. Shi, C. Liu, W.-B. Suo, and L. Gao, "Experimental characterization of shrinkage and desiccation cracking in thin clay layer," Applied Clay Science, vol. 52, no. 1-2, pp. 69-77, 2011.

[5] Q. Jiang, X.-T. Feng, J. Chen, K. Huang, and Y.-L. Jiang, "Estimating in-situ rock stress from spalling veins: a case study," Engineering Geology, vol. 152, no. 1, pp. 38-47, 2013.

[6] N.-W. Xu, C.-A. Tang, H. Li et al., "Excavation-induced microseismicity: microseismic monitoring and numerical simulation," Journal of Zhejiang University: Applied Physics and Engineering, vol. 13, no. 6, pp. 445-460, 2012.

[7] N. W. Xu, C. A. Tang, L. C. Li et al., "Microseismic monitoring and stability analysis of the left bank slope in Jinping first stage hydropower station in southwestern China," International Journal of Rock Mechanics \& Mining Sciences, vol. 48, no. 6, pp. 950-963, 2011.

[8] N. W. Xu, F. Dai, Z. Z. Liang, Z. Zhou, C. Sha, and C. A. Tang, "The dynamic evaluation of rock slope stability considering the effects of microseismic damage," Rock Mechanics and Rock Engineering, vol. 47, no. 2, pp. 621-642, 2014.

[9] G. Q. Chen, Y. Zhang, R. Q. Huang, F. Guo, and G. Zhang, "Failure mechanism of rock bridge based on acoustic emission technique," Journal of Sensors, vol. 2015, Article ID 964730, 11 pages, 2015.

[10] D.-S. Cheon, Y.-B. Jung, E.-S. Park, W.-K. Song, and H.-I. Jang, "Evaluation of damage level for rock slopes using acoustic emission technique with waveguides," Engineering Geology, vol. 121, no. 1-2, pp. 75-88, 2011.

[11] G.-Q. Chen, R.-Q. Huang, Q. Xu, T.-B. Li, and M.-L. Zhu, "Progressive modelling of the gravity-induced landslide using the local dynamic strength reduction method," Journal of Mountain Science, vol. 10, no. 4, pp. 532-540, 2013.

[12] J. Shen and M. Karakus, "Three-dimensional numerical analysis for rock slope stability using shear strength reduction method," Canadian Geotechnical Journal, vol. 51, no. 2, pp. 164-172, 2014.

[13] C. Tang, B. Shi, W. Gao, F. Chen, and Y. Cai, "Strength and mechanical behavior of short polypropylene fiber reinforced and cement stabilized clayey soil," Geotextiles and Geomembranes, vol. 25, no. 3, pp. 194-202, 2007.

[14] S. J. Li, H. Gao, D. M. Xu, and F. Meng, "Comprehensive determination of reinforcement parameters for high cut slope based on intelligent optimization and numerical analysis," Journal of Earth Science, vol. 23, no. 2, pp. 233-242, 2012. 
[15] X.-T. Feng and J. A. Hudson, "Specifying the information required for rock mechanics modelling and rock engineering design," International Journal of Rock Mechanics and Mining Sciences, vol. 47, no. 2, pp. 179-194, 2010.

[16] X. T. Feng and J. A. Hudson, Rock Engineering Design, CRC Press, Boca Raton, Fla, USA, 2011.

[17] Z.-M. Shi, Y.-Q. Wang, M. Peng, S.-G. Guan, and J.-F. Chen, "Landslide dam deformation analysis under aftershocks using large-scale shaking table tests measured by videogrammetric technique," Engineering Geology, vol. 186, pp. 68-78, 2015.

[18] Y. R. Li, B. P. Wen, A. Aydin, and N. P. Ju, "Ring shear tests on slip zone soils of three giant landslides in the Three Gorges Project area," Engineering Geology, vol. 154, pp. 106-115, 2013.

[19] S. Friedel, A. Thielen, and S. M. Springman, "Investigation of a slope endangered by rainfall-induced landslides using 3D resistivity tomography and geotechnical testing," Journal of Applied Geophysics, vol. 60, no. 2, pp. 100-114, 2006.

[20] M. Pieraccini, N. Casagli, G. Luzi et al., "Landslide monitoring by ground-based radar interferometry: a field test in Valdarno (Italy)," International Journal of Remote Sensing, vol. 24, no. 6, pp. 1385-1391, 2003.

[21] H.-H. Zhu, B. Shi, J.-F. Yan, J. Zhang, and J. Wang, "Investigation of the evolutionary process of a reinforced model. Slope using a fiber-optic monitoring network," Engineering Geology, vol. 186, pp. 34-43, 2015.

[22] H.-H. Zhu, B. Shi, J.-F. Yan, J. Zhang, C.-C. Zhang, and B.J. Wang, "Fiber Bragg grating-based performance monitoring of a slope model subjected to seepage," Smart Materials and Structures, vol. 23, no. 9, Article ID 095027, 2014.

[23] H.-H. Zhu, A. N. L. Ho, J.-H. Yin, H. W. Sun, H.-F. Pei, and C.-Y. Hong, "An optical fibre monitoring system for evaluating the performance of a soil nailed slope," Smart Structures and Systems, vol. 9, no. 5, pp. 393-410, 2012.

[24] H.-H. Zhu, J.-H. Yin, L. Zhang, W. Jin, and J.-H. Dong, "Monitoring internal displacements of a model dam using FBG sensing bars," Advances in Structural Engineering, vol. 13, no. 2, pp. 249-261, 2010.

[25] H. Zheng, J. A. Dijksman, and R. P. Behringer, "Shear jamming in granular experiments without basal friction," Europhysics Letters, vol. 107, no. 3, Article ID 34005, 2014.

[26] H. J. Wang, D. A. Liu, W. L. Gong, and L. Y. Li, "Dynamic analysis of granite rockburst based on the PIV technique," International Journal of Mining Science and Technology, vol. 2, pp. 275-283, 2015.

[27] M. S. Morse, N. Lu, A. Wayllace, J. W. Godt, and W. A. Take, "Experimental test of theory for the stability of partially saturated vertical cut slopes," Journal of Geotechnical and Geoenvironmental Engineering, vol. 140, no. 9, Article ID 04014050, 2014.

[28] H. O. Baba and S. Peth, "Large scale soil box test to investigate soil deformation and creep movement on slopes by Particle Image Velocimetry (PIV)," Soil and Tillage Research, vol. 125, pp. 38-43, 2012.

[29] R.-H. Chen, K. J. Kuo, Y.-N. Chen, and C.-W. Ku, "Model tests for studying the failure mechanism of dry granular soil slopes," Engineering Geology, vol. 119, no. 1-2, pp. 51-63, 2011.

[30] A. Aryal, B. A. Brooks, M. E. Reid, G. W. Bawden, and G. R. Pawlak, "Displacement fields from point cloud data: application of particle imaging velocimetry to landslide geodesy," Journal of Geophysical Research: Earth Surface, vol. 117, no. 1, Article ID F01029, 2012. 


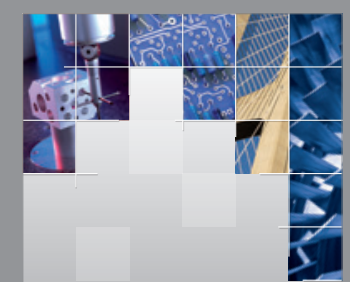

\section{Enfincering}
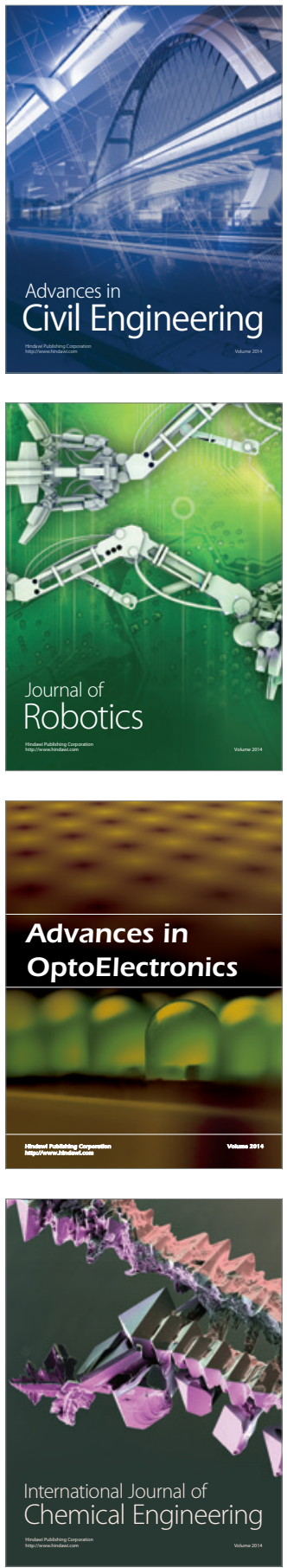

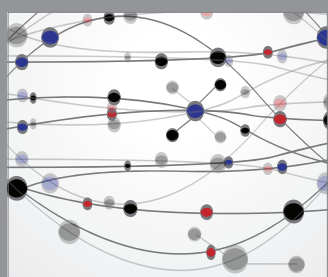

The Scientific World Journal

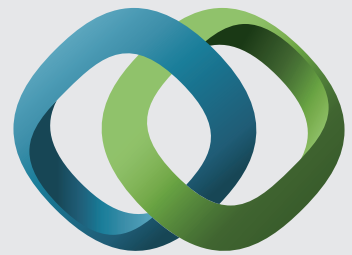

\section{Hindawi}

Submit your manuscripts at

http://www.hindawi.com
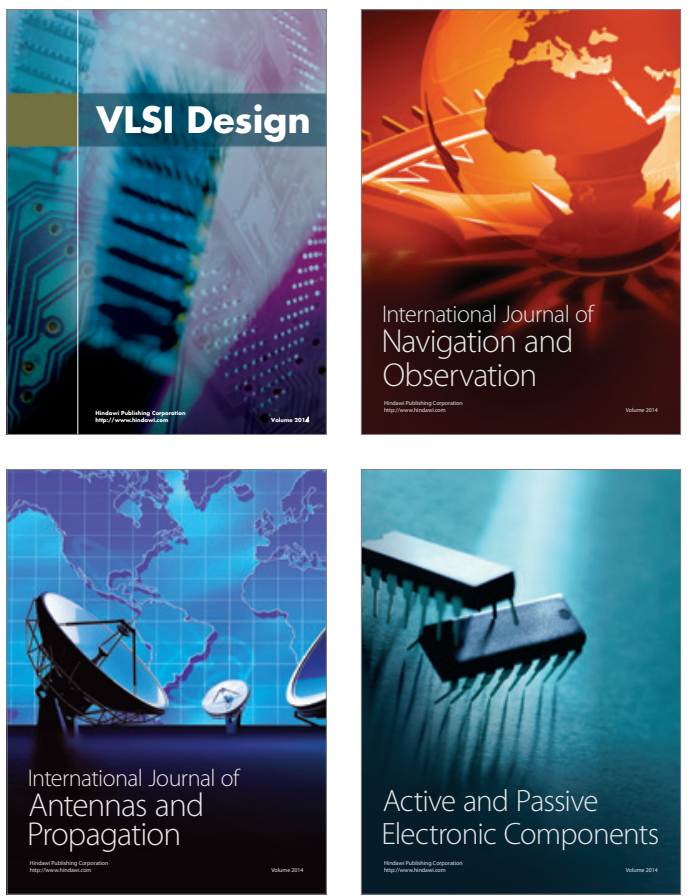
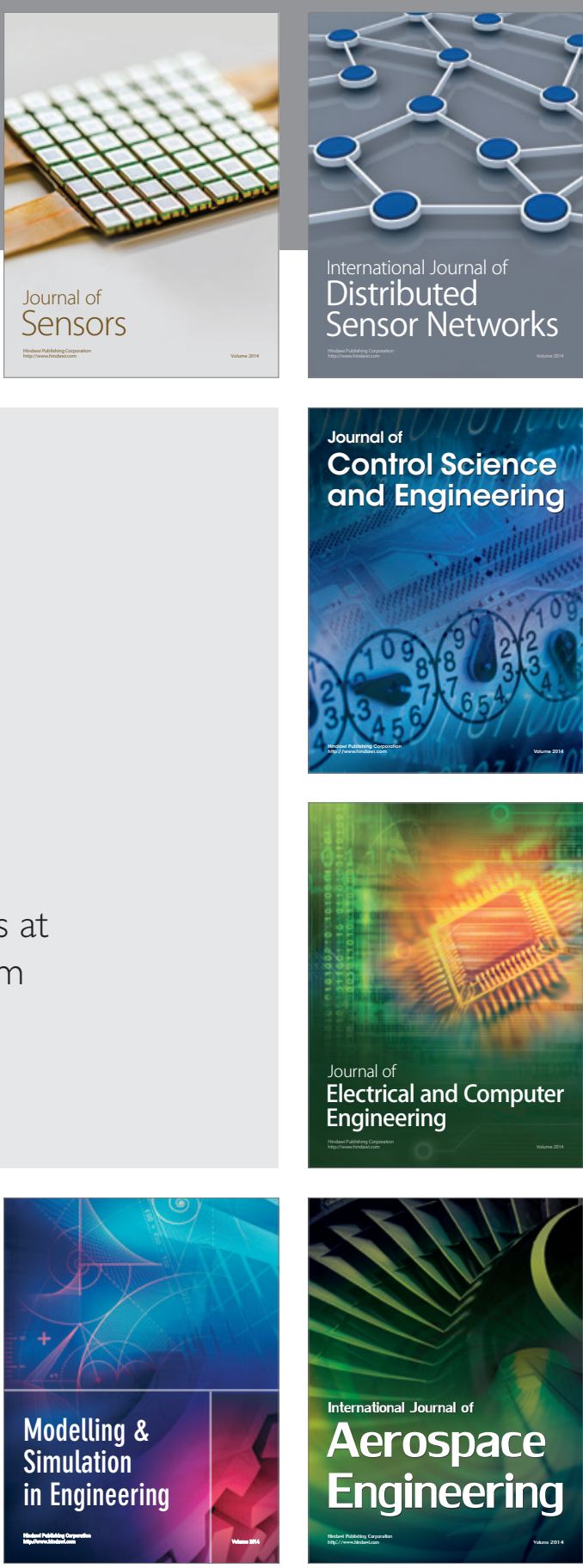

International Journal of

Distributed

Sensor Networks

Journal of

Control Science

and Engineering
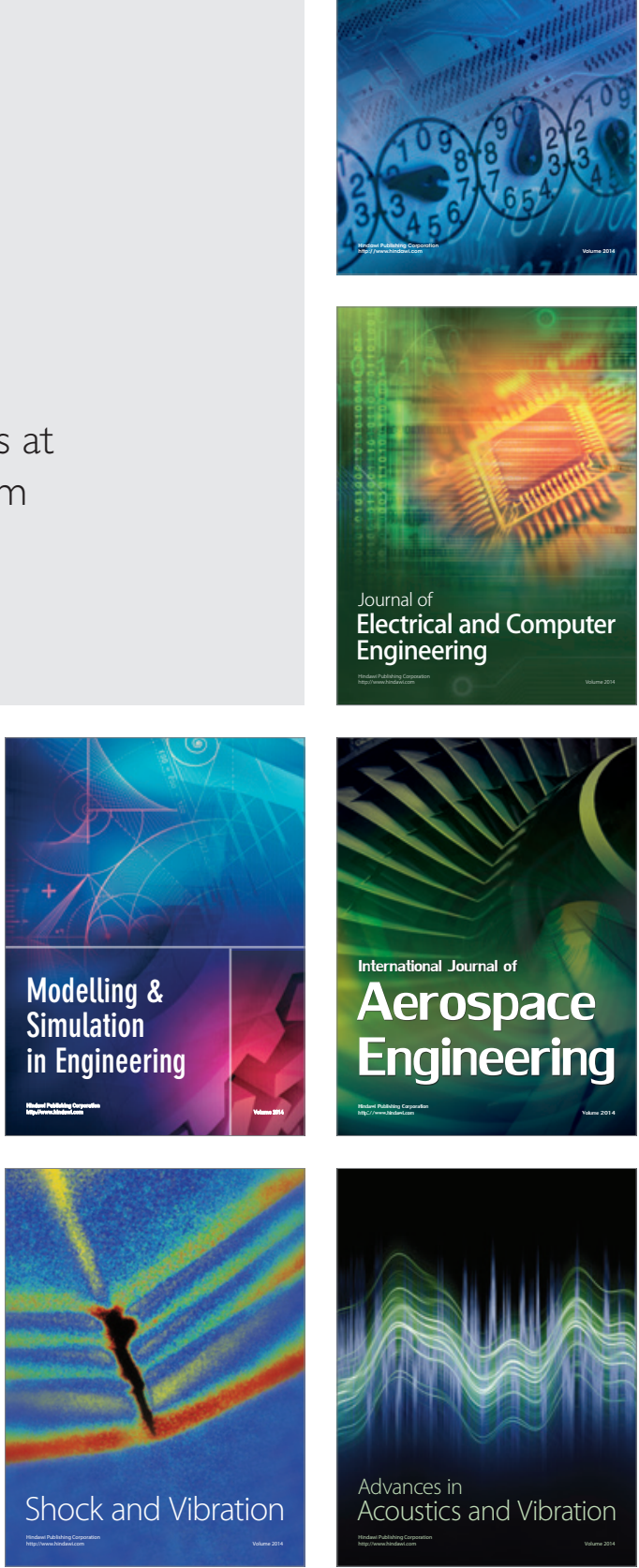